Revista Destaques Acadêmicos, Lajeado, v. 8, n. 4, 2016. ISSN 2176-3070 DOI: http://dx.doi.org/10.22410/issn.2176-3070.v8i4a2016.1219 www.univates.br/revistas

\title{
PROPOSTAS DE ABORDAGENS POR MEIO DE METODOLOGIAS ATIVAS NO ENSINO SUPERIOR
}

\author{
Adriana Magedanz ${ }^{1}$, Jane Herber ${ }^{2}$, Maria Cristina de Almeida Silva ${ }^{3}$
}

Resumo: Nos últimos anos se investigam novas metodologias para o processo de ensinar, que estimulem o aprender, possibilitando que os estudantes se tornem protagonistas. No nível superior, o trabalho com "Aprendizagem Baseada em Problemas", conhecida por ABP, está muito presente em artigos de docentes que desenvolvem estratégias enfatizando o aprendizado autodirigido, principalmente no que tange a área da saúde. Neste sentido, a partir dos encontros de estudos intitulado " $(\mathrm{Re})$ Construindo as práticas pedagógicas, integrando as diferentes áreas do CETEC", realizados ao longo de 2015 por um grupo de professores de graduação, buscou-se construir uma proposta experimental, enfocando aspectos pertinentes às metodologias ativas, em três disciplinas do Centro de Ciências Exatas e Tecnológicas (CETEC) do Centro Universitário UNIVATES, localizado em Lajeado-RS, são elas: Introdução às Ciências Exatas, Química Orgânica I e Tratamento de Efluentes. O principal desafio, do grupo de professores que conduziu o trabalho, foi desenvolver um processo de ensino e de aprendizagem que permitisse que o estudante fizesse efetivamente parte do procedimento, não como um mero espectador, e que o docente assumisse um papel de tutor ou mediador, rompendo com a clássica formação de sala de aula. Ao finalizar o semestre foi possível concluir que as atividades desenvolvidas, utilizando estratégias diferenciadas, conforme proposição inicial, possibilitaram aos estudantes o abandono da passividade tradicional, interagindo de maneira mais intensa, assimilando conceitos e aprimorando conhecimentos. Tais constatações evidenciam-se nos relatos dos discentes, que se mostraram muito mais participativos e autônomos, na busca por diferentes saberes.

Palavras-chave: Ensino. Aprendizagem Baseada em Problemas. Metodologias ativas. Matemática. Química. Engenharia.

1 Mestre em Ensino de Ciências Exatas, Centro Universitário UNIVATES, Professora, magedanza@univates.br

2 Mestre em Educação em Ciências e Matemática, Centro Universitário UNIVATES, Professora, jane.herber@univates.br

3 Mestre em Recursos Hídricos e Saneamento Ambiental, Centro Universitário UNIVATES, Professora, maria.silva9@univates.br 


\section{CONSIDERAÇÕES INICIAIS}

Ao identificar o desenvolvimento exponencial das tecnologias, o profissional docente necessita atualização constante, tendo que utilizar metodologias capazes de atrair, motivar, seus estudantes para os assuntos a serem abordados em sala de aula. Precisa ter presente que o conhecimento é acessado facilmente pelos mais variados meios, que o docente não é mais o detentor do saber.

No mundo atual, um questionamento que deve integrar as ações educacionais rotineiramente é: "Para quem e como ensinar e aprender?" Buscando pautar essa discussão, um grupo de docentes vinculados ao Centro de Ciências Exatas e Tecnológicas (CETEC), do Centro Universitário UNIVATES, apresentam alguns aspectos resultantes dos encontros de estudos realizados ao longo de 2015 e intitulado "(Re)Construindo as práticas pedagógicas, integrando as diferentes áreas do CETEC".

\section{ENSINAR E APRENDER SE COMPLETAM}

Na busca por respostas, sugere-se iniciar pela definição dos termos. De acordo com o dicionário da Língua Portuguesa Larousse Cultural (p. 77 e 362), "ensinar" está definido como: "Transmitir conhecimentos; instruir. - Educar. Doutrinar. - Amestrar, adestrar. - Treinar. - Domesticar, domar (falando-se de animais). - Indicar, mostrar". Consultando a mesma fonte, "aprender" possui a seguinte definição: "Adquirir conhecimento de, ficar sabendo, instruir-se. Tornar-se apto, capaz, em consequência da experiência e observação". Uma velha anedota pode auxiliar na diferenciação dos dois termos: É possível "ensinar" um cachorro a falar? Sim, e é muito fácil. O difícil é fazê-lo "aprender".

Dito isso, e inspirando-se em Abreu e Masetto apud Gil (2012, p.6), pode-se refletir sobre uma das mais importantes opções feitas pelo professor: "entre o ensino que ministra ao aluno e a aprendizagem que este adquire". Conforme Gil (2012, p. 7), "à medida que a ênfase é colocada na aprendizagem, o papel predominante do professor deixa de ser o de ensinar, e passa a ser o de ajudar o aluno a aprender". É preciso voltar-se para uma educação contrária aquela denominada por Paulo Freire (1987, p. 33) como "bancária". Com isso, o ensino passará a ser mais do que mera transmissão de conhecimentos e o professor, que deixará de ser a figura central em sala de aula, tornar-se-á um facilitador da aprendizagem.

Com relação ao conceito de aprendizagem, há muitas definições. Neste sentido, Gil (2012, p. 80) destaca:

Uma das mais utilizadas nos textos que tratam de Educação é a de Gagné (1980, p.6): “A aprendizagem é inferida quando ocorre uma mudança ou modificação no comportamento, mudança esta que permanece por períodos relativamente longos durante a vida do 
indivíduo." Assim, pode-se dizer que ocorre aprendizagem quando uma pessoa manifesta aumento da capacidade para determinados desempenhos em decorrência de experiências por que passou. O conceito de aprendizagem é, pois, bastante complexo. [...] para fins educacionais, pode-se definir aprendizagem como o processo de aquisição de conhecimentos, desenvolvimento de habilidades e mudança de atitudes em decorrência de experiências educativas, tais como aulas, leituras, discussões, pesquisas etc.

A partir do que foi exposto, percebe-se a importância de compreender o que de fato representa o aprendizado. Nesta tentativa, poderíamos parafrasear Richard Burton ${ }^{4}$ e analisar a aprendizagem através de um ciclo, representado na Figura 1 abaixo.

Figura 1 - Ciclo da aprendizagem

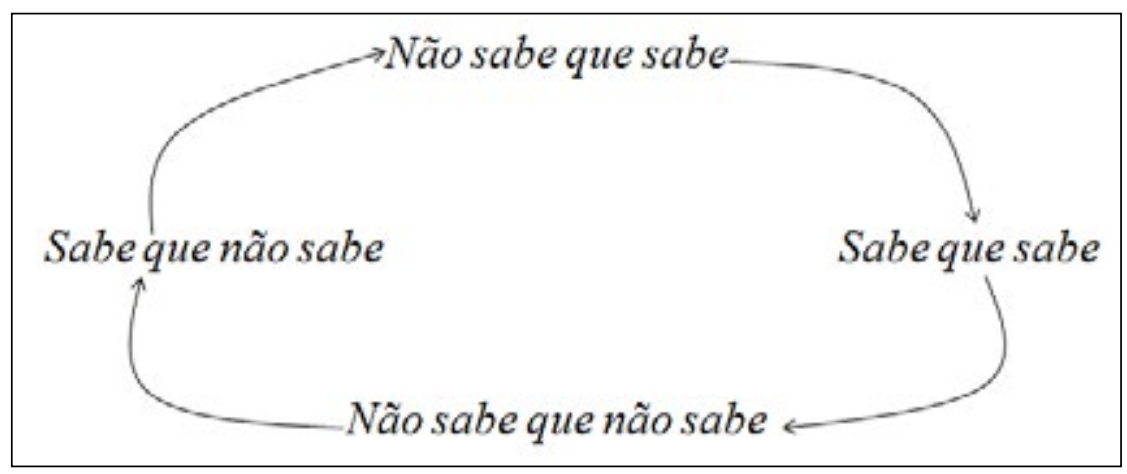

Fonte: Das autoras, com base em Richard Burton.

Inicialmente, todos "não sabemos que não sabemos" - sim, somos tolos. Até que surge uma crucial pergunta, que nos defronta com a cruel e mais simples percepção: "sabemos que não sabemos". E aí partimos para a aquisição de conhecimentos, desenvolvimento de habilidades e mudança de atitudes, chegando ao ponto em que já "não sabemos que sabemos" e precisamos acordar para a realidade e retomar o foco. Neste momento, percebemos que aprendemos, ou seja, "sabemos que sabemos". Mas, como o sábio não se exibe, volta às origens e já "não sabe que não sabe". É, de fato, aprender é um ciclo, que se repete ao longo de toda vida.

Buscando traçar algum indício de resposta à indagação apresentada inicialmente: "Para quem e como ensinar e aprender?", inspiramo-nos nas palavras de Paulo Freire (1987, p.39), “ninguém educa ninguém, ninguém

4 "Há quatro espécies de homens: O que não sabe e não sabe que não sabe: é tolo - evita-o; O que não sabe e sabe que não sabe: é simples - ensina-o; $O$ que sabe e não sabe que sabe: ele dorme - acorda-o; O que sabe e sabe que sabe: é sábio - segue-o" (Richard Burton). 
educa a si mesmo, os homens se educam entre si, mediatizados pelo mundo". Ensinar e aprender não são funções separáveis. Ensinamos e aprendemos mutuamente. E para quem? Para todos envolvidos no processo, ou seja, para a sociedade em geral.

\section{APRENDIZAGEM BASEADA EM PROBLEMAS - ABP}

A contemporaneidade exige, cada vez mais, a qualificação profissional docente para que se possa aperfeiçoar as metodologias utilizadas em sala de aula de modo que os estudantes passem de espectadores para protagonistas, buscando o conhecimento por métodos de aprendizagem variados, o docente precisa se reconstruir a cada dia, atualizando-se para acompanhar a rapidez com que o conhecimento evolui. Atualmente o acesso ao conhecimento é imenso, qualquer um pode pesquisar e aprender sobre suas dúvidas considerando as Novas Tecnologias da Informação e Comunicação - NTICs (RODRIGUES, 2009).

A ABP (Aprendizagem Baseada em Problemas) é uma estratégia de ensino que está centrada no aluno. Possui uma metodologia ativa, fazendo com que os estudantes trabalhem com o objetivo de conhecer, compreender e solucionar situações desafiadoras. A metodologia é Problematizadora, está centrada nas perguntas, na pesquisa, no aprender a pensar, a criar hipóteses e testá-las (com base no conhecimento prévio e nas novas descobertas); tem como base a identificação e resolução de problemas, onde o estudante deve aprender a fazer perguntas e a trabalhar cooperativamente para respondêlas. Os discentes não copiam nem absorvem ideias do mundo externo, mas constroem seus conceitos por meio da observação e experimentação ativa e pessoal. A história do sujeito particulariza a história dos conhecimentos desse sujeito e vice-versa.

Para Berbel (1998, p.142) a ABP, metodologia da problematização, é uma estratégia de ensino, estudo e trabalho que pode ser utilizada sempre que for oportuno, em situações onde os temas estejam relacionados com assuntos da sociedade.

Segundo Freire (1995):

Ninguém começa a ser educador numa certa terça-feira às quatro horas da tarde. Ninguém nasce educador ou é marcado para ser educador. A gente se faz educador, a gente se forma como educador permanente, na prática e na reflexão sobre a prática.

Já para Araújo e Sastre (2009), tratando-se de construção do saber, a docência é marcada pelo trabalho de estruturar os componentes de estudo, orientar, estimular e provocar o participante a construir o seu próprio saber, partindo do princípio de que não há resposta feita, a cada experiência/prática novos enunciados/conceitos. 
O educador deve ser aquele que possibilita o acesso ao conhecimento a partir de informações bem fundamentadas. Precisa assumir postura ética e responsável frente as problematizações, aproveitando a cultura digital, as ferramentas tecnológicas para construir, representar e sintetizar as informações em uma produção coletiva. O docente fará parte do desafio na orientação ao processo metodológico a ser desenvolvido e no planejamento. Abordando conceitos atuais e incentivando os estudantes para que façam levantamento de dados, estruturando e desenvolvendo projetos. Os discentes definem o problema, estudam teorias, realizam experimentos, bem como sínteses, conclusões, avaliação e consequências (ARAÜJO; SASTRE, 2009, p.34).

O estudante é o núcleo do processo educativo na ABP. Ele é responsável por sua aprendizagem. Torna-se autônomo e, consequentemente, desenvolve sua autoria por meio de um aprendizado eficaz. Pois, ao elaborar questões, acaba ampliando-as no entorno social. Desenvolve habilidades de comunicação, ampliando sua visão de mundo (ARAÚJO; SASTRE, 2009, p.34).

Segundo Araújo e Sastre (2009) a ABP prioriza e oportuniza o processo de aprendizagem por meio de problematizações concretas, reais. Desenvolve a responsabilidade social e a inovação, transformando a realidade e priorizando a justiça social.

Na ABP, com base, novamente, em Araújo e Sastre (2009), seguem-se os seguintes passos:

* Análise do problema - Contexto amplo, relevância, estratégias para resolução;

* Fase - debate, planejamento, bibliografia;

* Resolução do Problema - Cabe ao professor-tutor estabelecer o planejamento das ações, escolher o método;

* Relatório - Revisão do projeto, conclusão e finalização. Representação do que foi estudado. Cumprimento de prazos;

* Avaliação - Contribuições do projeto.

Já tomando por base a Harvard Medical School, a forma de aplicação do método é apresentada no esquema abaixo ${ }^{5}$ :

* Fase I:

- Identificação do(s) problema(s);

- Formulação de hipóteses;

- Solicitação de dados adicionais;

- Identificação de temas de aprendizagem;

5 Wetzel MS. An update on problem based learning at Harvard Medical School. Ann Com Orient Educ. 1994;7:237-47. 
- Elaboração do cronograma de aprendizagem;

- Estudo independente.

* Fase II:

- Retorno ao problema;

- Crítica e aplicação das novas informações;

- Solicitação de dados adicionais;

- Redefinição do problema;

- Reformulação de hipóteses;

- Identificação de novos temas de aprendizagem;

- Anotação das fontes.

* Fase III:

- Retorno ao processo;

- Síntese da aprendizagem;

- Avaliação.

De forma geral, é possível identificar alguns objetivos específicos pertinentes ao ensino e aprendizagem na adesão pela metodologia de ABP, são eles:

* Promover a aquisição de conhecimentos pelos alunos;

* Desenvolver habilidades e atitudes profissionais desejáveis;

* Utilizar um problema para iniciar, enfocar e motivar a aprendizagem de novos conceitos;

* Possibilitar que o aluno utilize diferentes processos mentais, como capacidade de levantar hipóteses, comparar, analisar, interpretar e avaliar;

* Medrar a habilidade de assumir responsabilidade por sua formação.

Não há dúvida que a $\mathrm{ABP}$ é um instrumento valioso na formação do profissional da contemporaneidade. Mas, também é evidente que para a sua implantação há necessidade de um considerável esforço institucional. A tarefa inclui mudanças na forma de avaliação, apontando para uma nova visão no papel do docente inserido no processo ensino/aprendizagem. Além disso, requer investimentos em infraestrutura, como: adaptações de ambientes, melhoria das bibliotecas, entre outros.

Especificamente sobre a avaliação, ao adotar a $\mathrm{ABP}$ o "processo de avaliação aliado ao processo de aprendizagem" (MASETTO, 2012, p. 165), com diversidade de métodos avaliativos, experimentando diferentes mecanismos, prezando pela busca à qualificação do sistema educativo. A avaliação precisa contemplar os objetivos vinculados às metodologias ativas.

Conforme Luckesi (1999) "para não ser autoritária e conservadora, a avaliação tem a tarefa de ser diagnóstica, ou seja, deverá ser o instrumento 
dialético do avanço, terá de ser o instrumento da identificação de novos rumos". A avaliação inserida no processo de aprendizagem, possibilitando a negociação com os estudantes, visando a melhoria e aprimoramento deste. p. 19):

O processo avaliativo dentro da ABP deve ser, segundo Esteban (2003,

[...] momento capaz de revelar o que o aluno já sabe, os caminhos que percorreu para alcançar o conhecimento demonstrado, seu processo de construção do conhecimento, o que o aluno não sabe e o caminho que deve percorrer para vir a saber, o que é potencialmente revelado em seu processo, suas possibilidades de avanço [...]

Esse caminho de mudanças, com certeza, ocasionará inúmeros desafios, principalmente com o rompimento dos modelos de ensino tradicional e a formação de profissionais competentes.

\section{ALGUMAS ATIVIDADES DESENVOLVIDAS}

A seguir, serão apresentadas algumas das atividades desenvolvidas com os discentes nas disciplinas de Introdução às Ciências Exatas, Química Orgânica I e Tratamento de Efluentes, ministradas pelas autoras desta escrita. A fim de preservar os discentes, optou-se por identificá-los, no decorrer do texto, como A1 (Aluno 1), A2 (Aluno 2) e, assim, sucessivamente.

\subsection{Introdução às Ciências Exatas}

Na última reestruturação curricular dos cursos do CETEC foi incluída a disciplina de "Introdução às Ciências Exatas", obrigatória e pré-requisito em algumas situações. Dentre os objetivos da mesma, em relação aos discentes que optam em cursá-la, está: "Desenvolver autonomia, por meio de atividades diversificadas, como: investigações práticas, problemas desafio e uso de tecnologias de comunicação e informação". Visando a também alcançar esta meta, foi proposto aos alunos uma aula sobre trigonometria com uso do software Geogebra. Para tanto, ficou acordado que os estudantes, em duplas, seriam responsáveis em providenciar um notebook com a instalação do programa e a professora disponibilizaria, no ambiente virtual da disciplina, um roteiro com a descrição, passo a passo, da atividade a ser desenvolvida (criação de um círculo trigonométrico interativo).

Uma vez descrita a tarefa, os discentes perceberam-se diante de um desafio que exigia aliar diferentes habilidades: leitura e interpretação de um roteiro, conhecimentos básicos de ferramentas computacionais e noções sobre os elementos do círculo trigonométrico. Identificado o problema, iniciou-se a busca por hipóteses de solução, neste caso, a atividade dava-se por concluída diante da visualização do círculo trigonométrico interativo construído com auxílio do software Geogebra. Percebeu-se que o processo gerou discussões nas 
duplas referentes a interpretação do roteiro - "Será que estamos no caminho certo?" (A3), bem como no que tange às aplicações das ferramentas computacionais "Tudo indica que está correto porque a interatividade está funcionando" (A4) - e ao reconhecimento de conceitos matemáticos presentes - "Além disso, os valores das funções seno, cosseno e tangente fazem sentido ao longo do círculo trigonométrico" (A4). Alguns alunos, já trilhado um trajeto do roteiro, se viam obrigados a retornar a algum ponto, percebendo, sozinhos, que o resultado não condizia com a realidade prevista - "Veja, a imagem visualizada no monitor não está de acordo com a figura deste item do roteiro, precisamos rever os passos para descobrir onde falhamos" (A5).

Estudantes ativos, trabalhando de forma cooperativa, com metas definidas, estimulando a autonomia, respeitando as diferenças, despertando diálogos, promovendo interações, desenvolvendo habilidades... características da $\mathrm{ABP}$ presentes na atividade proposta em sala de aula durante a construção do círculo trigonométrico interativo no software Geogebra.

Figura 2-Construção do círculo trigonométrico interativo no software Geogebra

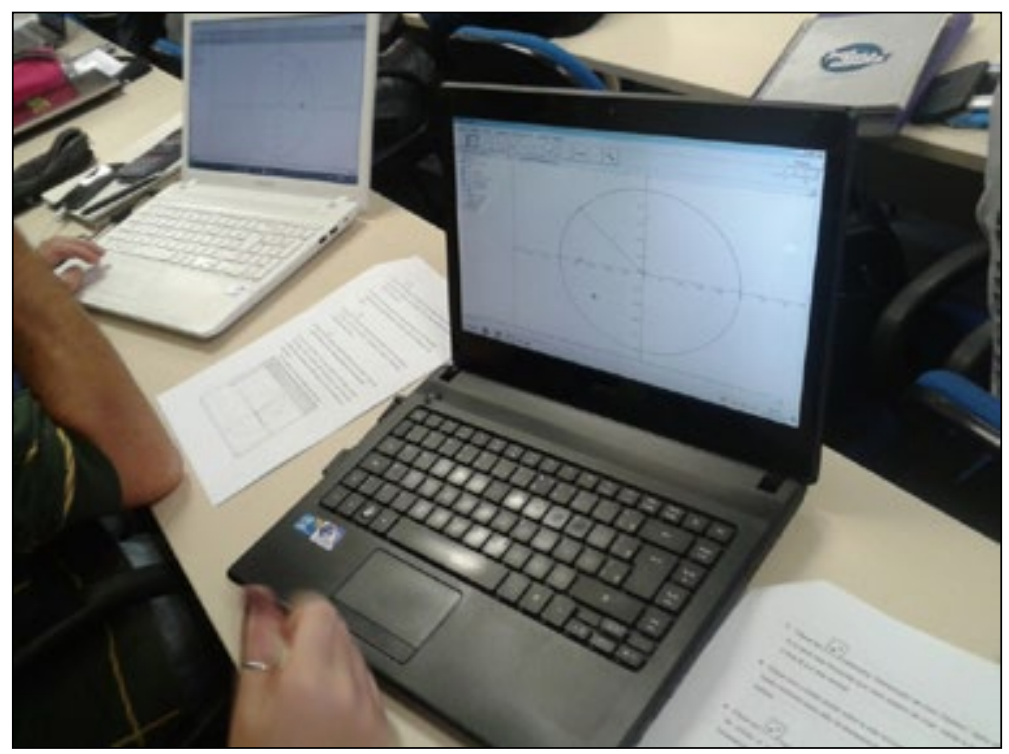

Fonte: Arquivo pessoal (2015).

Foi um trabalho diferente, já que a trigonometria é um assunto bastante utilizado ao longo dos cursos do CETEC, principalmente na área das engenharias, e o círculo trigonométrico não foi entregue pronto para cada aluno, a construção permitiu analisar o processo com maior detalhamento e, consequentemente, trouxe novas percepções sobre o estudo posterior, referente às funções trigonométricas. De forma geral, a aula teve boa repercussão na turma, foi um desafio aos alunos, que desenvolveram autonomia ao longo da 
atividade, e a professora, que buscou romper com uma forma tradicional de ensino.

\subsection{Química Orgânica I}

Com a finalidade de trabalhar com metodologias ativas e, neste caso, com a ABP, na disciplina de "Química Orgânica I", a partir da apresentação das habilidades e competências a serem desenvolvidas durante o semestre, a docente propôs que os graduandos de Farmácia e Engenharia Química procurassem respostas para questões do cotidiano que, de alguma forma, teriam relação com a sua escolha profissional. A partir disso, solicitou que formassem grupos por afinidade de tema e realizassem uma pesquisa sobre os assuntos a serem abordados, procurando relacionar com os conteúdos que seriam desenvolvidos na disciplina ao longo das aulas. Neste trabalho, optou-se por descrever duas atividades realizadas pelos estudantes: uma delas voltada para o descarte adequado de medicamentos e outra voltada para o cuidado que gestantes devem ter ao ingerir medicamentos.

Na primeira situação, as estudantes disseram que, em algumas farmácias, identificavam facilmente recipientes adequados para a coleta de medicamentos vencidos ou que não são mais utilizados pela população. Fizeram uma pesquisa com o objetivo de verificar quantas e quais farmácias do município recolhiam os medicamentos vencidos ou sobras e se essas pertenciam a uma rede ou não. Também pesquisaram sobre o problema do descarte incorreto de medicamentos, considerando seus princípios ativos e a contaminação da fauna aquática, principalmente, pois a partir da leitura de artigos relacionados perceberam que muitas pessoas descartam os medicamentos na pia ou no vaso sanitário. Enquanto outras os jogam no lixo doméstico. Perceberam que a contaminação dos rios e mares é preocupante, pois além dos outros contaminantes, os medicamentos podem provocar mutações nos organismos vivos, como peixes, e que esses fazem parte da alimentação dos humanos, bem como de outros animais. Ao mencionar a contaminação do solo, perceberam que os lençóis freáticos estão expostos aos mais variados tipos de resíduos, mas os fármacos ganham destaque. No decorrer da atividade descobriram que na instituição existe uma pesquisa envolvendo o tema. No que diz respeito ao conteúdo de Química Orgânica I, estudaram os princípios ativos dos medicamentos mais utilizados pela população, como analgésicos, antibióticos e anti-histamínicos. Fazendo um estudo da composição química por meio das fórmulas químicas de cada um, estudando as funções orgânicas presentes, fórmulas moleculares, estruturais e nomenclaturas. Para a discente A6, "a maneira com que o conteúdo foi abordado, pelos trabalhos de pesquisa e posterior apresentação para os colegas, facilitou a compreensão do mesmo, pois nas aulas seguintes foi possível relacionar o conteúdo com o tema do trabalho".

O grupo que pesquisou sobre a ingestão de medicamentos por gestantes, encontrou que, em muitos casos, os medicamentos podem causar danos 
irreparáveis ao feto, desde má formação, demência, até a morte. Associaram a sua pesquisa ao caso da Talidomida, medicamento utilizado por gestantes no passado. Um dos problemas ocasionados foi o encurtamento dos ossos longos dos membros superiores e inferiores e, em alguns casos, observou-se a ausência de mãos e de pés nos recém-nascidos. Após lerem artigos sobre o assunto fizeram relação com o conteúdo de isomeria e associaram as funções orgânicas. Para a discente A7, "foi mais fácil entender o conteúdo de isomeria no momento em que a professora abordou, pois o nosso grupo tinha estudado isomeria para apresentar o trabalho, acredito que essa metodologia permite com que se tenha um melhor aprendizado". A pesquisa permitiu ainda que os estudantes percebessem a importância de ingerir medicamentos somente quando indicado pelo médico e, principalmente, no caso de gestantes. Além de identificarem que a Talidomida foi proibida e está voltando ao mercado devido aos mecanismos de ação como droga terapêutica, no combate a cerca de sessenta patologias.

É importante destacar que a maioria dos discentes relatou que encontrou dificuldades no início da atividade proposta, pois para muitos era o primeiro contato com o tema de pesquisa, o que dificultou a relação com os conteúdos de Química Orgânica. Disseram que foi de suma importância os momentos de aula para a realização das pesquisas, pois tiveram o auxílio da professora e dos demais colegas.

\subsection{Tratamento de Efluentes}

A disciplina "Tratamento de Efluentes" faz parte da formação específica dos cursos de Engenharia Ambiental, Civil e Química. Como é um grupo diversificado, se faz necessária uma aula de introdução que nivele, estimule e provoque os alunos, para enfocar a sua importância. A mesma é trabalhada a partir da exposição de problemas ambientais relacionados à qualidade de águas, como eutrofização e mortandade de peixes, e sua quantidade, como estiagem, que são vistos atualmente em alguns estados brasileiros.

Dado este primeiro momento, os alunos fizeram pesquisas, para na segunda aula terem embasamento para discussão na turma das possíveis causas destes problemas. É consenso que a sua ocorrência é devida às atividades humanas, que desequilibram o ciclo deste elemento. Também foram propostas algumas sugestões para melhoria, e foi escolhida uma forma de mitigação permanente, a fim de minimizar os impactos nos corpos hídricos. Sendo assim, os alunos concordaram que a conscientização e educação ambiental é uma solução para este impasse e, principalmente, o maior controle quanto à disposição de efluentes, tanto domésticos e industriais, em corpos hídricos. Desta forma, o tratamento dos mesmos se faz necessário e todos os futuros profissionais podem ter atribuições para desenvolver esta atividade.

Como exemplo, na primeira aula foi exposta uma reportagem a respeito da mortandade de peixes que ocorreu no Rio dos Sinos, no ano de 
2006. A atividade de discussão se deu na aula seguinte e foi verificado que esta tragédia teve como causa principal os despejos de matéria orgânica, industrial e doméstica naquela região. A partir disso, foi facilitado o trabalho da próxima etapa da disciplina, relacionada aos parâmetros de qualidade de água. Foi de fácil entendimento que o "oxigênio dissolvido" em águas tende a diminuir quando a matéria orgânica, medida indiretamente sob a forma de "demanda bioquímica de oxigênio", aumenta.

De acordo com o aluno A1, "a problematização do assunto, empregando exemplos reais, auxiliou para o entendimento do conceito de qualidade de águas e, consequentemente, a sua importância". Já conforme o aluno A2, "como as causas da poluição e contaminação das águas foram bem entendidas, facilitou a compreensão dos tópicos subsequentes vistos na disciplina". Além disso, como é um tema presente no cotidiano de todos, houve a participação dos alunos em aula, relatando as más condições dos corpos hídricos próximos de suas residências, o que estimulou a participação de todos e a realização de aulas dialogadas.

\section{CONSIDERAÇÕES FINAIS}

Talvez seja consenso, na atualidade, que o "ser professor" exige cada vez mais do profissional docente, tendo em vista a velocidade com que o conhecimento e as tecnologias evoluem e que não há como manter a mesma metodologia do século passado, do ano passado, da aula passada.

Para desenvolver conteúdos em sala de aula, é necessário rever estratégias metodológicas e procurar o que de fato é adequado para introduzir esse ou aquele conhecimento. Deve-se considerar que, em algumas situações, ou seja, na apresentação de determinados assuntos, é difícil fugir dos métodos tradicionais, o que também foi constatado pelo grupo de professores no decorrer do semestre, enquanto buscavam construir ações diferenciadas em sala de aula, visando contemplar a inserção de metodologias ativas.

Por outro lado, a reflexão e a análise das práticas educativas, associadas a busca do "ser professor" rompendo com a forma tradicional de ensino, permitiram desenvolver conteúdos a partir do questionamento dos alunos, das suas dúvidas, e, com isso, apontou como um estímulo, incentivando e, consequentemente, desencadeando no uso da ABP.

Ao finalizar as atividades do semestre, se conclui que a proposta de fazer uso da ABP possibilitou que os estudantes se tornassem protagonistas do processo de ensino e de aprendizagem, constatação efetuada a partir dos relatos dos próprios discentes. Como na turma da "Química Orgânica I", onde ambos os grupos, ao apresentarem o trabalho, relataram que, nas primeiras leituras que fizeram, encontraram dificuldades, mas, durante o processo de pesquisa, tiveram o auxílio do professor e, depois dos conteúdos serem apresentados em exercícios de aplicação, relataram que tiveram mais facilidade em entender. 
Além disso, a inclusão da $\mathrm{ABP}$, e outras metodologias ativas, também se torna ferramenta didática importante, principalmente quando há turmas com alunos de cursos, que possuem conhecimentos prévios e interesses distintos. Nas duas disciplinas envolvendo, principalmente, os cursos de Engenharia, "Introdução às Ciências Exatas" e "Tratamento de Efluentes", verificou-se que a técnica foi uma forma de nivelamento inicial eficiente, para todos terem um acompanhamento satisfatório do desenvolvimento da disciplina. Isso também pôde ser comprovado a partir das notas obtidas na tarefa, bem como ao longo do semestre, quando o conhecimento foi pré-requisito para novos aprendizados.

Ainda assim, para que essa técnica seja amplamente utilizada e aceita, é necessária uma adaptação dos acadêmicos e também dos docentes. A quebra do paradigma, que visa o método tradicional, na qual o professor é o detentor do conhecimento e experiências, é e será motivo para muitas discussões, pois hoje, da forma como os currículos estão distribuídos, somente alguns assuntos abordados nas disciplinas específicas poderiam ser explorados com sucesso a partir do emprego da ABP e demais estratégias, as quais exigem um afastamento da "zona de conforto" e permeiam a "zona de risco"6.

Para finalizar, não resta dúvida que a presença dos conteúdos ainda requer um maior planejamento quanto ao uso das metodologias ativas em geral, passíveis de emprego em sala de aula, buscando garantir a satisfação de todos envolvidos no processo educacional.

\section{REFERÊNCIAS}

ARAÚJO, J. L. Tecnologia na sala de aula: desafios do professor de Matemática. Disponível em: <www.mat.ufmg.br/ jussara/artigos/Araujo\%20(2005).pdf > . Acesso em 12 set. 2014.

ARAÚJO, U. F.; SASTRE, G. (orgs.) Aprendizagem Baseada em Problemas no Ensino Superior. São Paulo: Summus, 2009.

\section{BERBEL, N. A. N. A problematização e a aprendizagem baseada em problema.}

Revista Interface. Comunicação, Saúde, Educação. V.2, 1998. Disponível em: <www. scielo.br/pdf/icse/v2n2/08>. Acesso em: 12 dez. 2015.

ESTEBAN, M. T. (Org.) Escola, Currículo e avaliação. Série Cultura Memória e currículo, vol. 5. São Paulo: Cortez, 2003.

FREIRE, P. A educação na cidade. 2. ed. São Paulo: Cortez, 1995.

6 Nas palavras de Borba e Penteado (2001) apud Araújo (2005, p.4): “A zona de conforto é uma situação vivida pelo professor na qual quase tudo é previsível, conhecido e controlável em suas aulas. Não há muito movimento em sua prática: ela se repete cotidianamente. [...] Na zona de risco, imperam a imprevisibilidade e a incerteza. O surgimento de situações inesperadas é uma constante e o professor deve estar preparado para enfrentá-las." 
Pedagogia do Oprimido. 17a edição. Rio de Janeiro: Paz e Terra, 1987.

Disponível em: <www.letras.ufmg.br/espanhol/pdf\%5Cpedagogia_do_oprimido. pdf>. Acesso em: 29 set. 2014.

GIL, A. C. Didática do ensino superior. $1^{\mathrm{a}}$ edição. $7^{\mathrm{a}}$ reimpressão. São Paulo: Atlas, 2012.

LUCKESI. C. C. Avaliação da aprendizagem escolar. 9. ed. São Paulo: Cortez, 1999.

MASETTO, M. T. Competência pedagógica do professor universitário. 2. ed. rev. São Paulo: Summus, 2012.

RIBEIRO, L. R. de C. Aprendizagem baseada em problemas (PBL): uma experiência no ensino superior. EdUFSCar. 2008. 151p.

RODRIGUES, N. C. Tecnologias de informação e comunicação na educação: um desafio na prática docente. Fórum Linguístico, Florianópolis, 2009. V.6, n.1, p. 1-22. 